Горбунова Наталия Владимировна, аспирант кафедры «Технологии продуктов питания», Саратовский государственный аграрный университет имени Н.И. Вавилова. Россия.

Евтеев Александр Викторович, ведущий специалист учебно-научно-испытательной лаборатории по определению качества пищевой и с.-х. продукции, Саратовский государственный аграрный университет имени Н.И. Вавилова. Россия.

Банникова Анна Владимировна, $\partial-p$ техн. наук, доцент кафедры «Технологии продуктов питания», Сара- товский государственный аграрный университет имени Н.И. Вавилова. Россия.

Ларионова Ольга Сергеевна, $\partial-p$ биол. наук, проф., зав. кафедрой «Микробиология, биотехнология и химия», Саратовский государственный аграрный университет имени Н.И. Вавилова. Россия.

410005 , г. Саратов, ул. Соколовая, 335.

Тел.: (8452) 69-25-32.

ключевые слова: ультразвуковая экстракция; бетацианины; бетаксантины; полифеноль; глубокая переработка растительного сырья.

\title{
EVALUATION OF THE USE ULTRASOUND TO OBTAIN EXTRACTS WITH HIGHER CONTENT OF BIOLOGICALLY ACTIVE SUBSTANCES FROM THE PRODUCTS OF COMPLEX PROCESSING OF CROP PRODUCTION
}

Gorbunova Natalia Vladimirovna, Post-graduate Student of the chair "Food Technology", Saratov State Agrarian University named after N.I. Vavilov. Russia.

Evteev Aleksandr Viktorovich, Leading specialist of the Laboratory of Foods and Agricultural Products Quality Determination, Saratov State Agrarian University named after N.I. Vavilov. Russia.

Bannikova Anna Vladimirovna, Doctor of Technical Sciences, Associate Professor of the chair "Food Technology", Saratov State Agrarian University named after N.I. Vavilov. Russia.

Larionova Olga Sergeevna, Doctor of Biological Sciences, Professor, Head of the chair "Microbiology, biotechnology and chemistry", Saratov State Agrarian University named after N.I. Vavilov. Russia.

Keywords: ultrasonic extraction; betacyanins; betaxanthins; polyphenols; deep processing of plant raw materials.
The perceptive task facing producers of agricultural products is the processing of crop wastes, and beet production is no exception. For example, with deep processing of secondary raw materials, it is possible to obtain such a particularly valuable substance as betalaines, which possess antioxidant and anti-inflammatory properties, which are water-soluble nitrogen-containing pigments and synthesized from amino acid tyrosine into two structural groups. As a result of the study, the possibility of using ultrasonic extraction for the purpose of obtaining a complex of antioxidants from beet tops was evaluated. As a result of the study, it was shown that the highest level of extraction of biologically active substances was observed when using ultrasonic extraction. At the same time, their level was higher by approximately $45 \%$, which contributes to savings.

\section{СЦЕНАРИИ ГЛОБАЛЬНОГО ПОТЕПЛЕНИЯ И ПРОГНОЗЫ ИЗМЕНЕНИЙ АГРОКЛИМАТИЧЕСКИХ РЕСУРСОВ ПОВОЛЖЬЯ}

\author{
КОРСАК Виктор Владиславович, Саратовский государственный аграрный университет \\ имени Н.И. Вавилова
}

КРАВЧУК Алексей Владимирович, Саратовский государственный аграрный университет имени Н.И. Вавилова

\section{ПРОКОПЕЦ Роман Викторович, Саратовский государственный аграрный университет имени} Н.И. Вавилова

НИкИШАНОВ Александр Николаевич, Саратовский государственный аграрный университет имени Н.И. Вавилова

\author{
АРЖАНУХИНА Екатерина Владимировна, Саратовский государственный аграрный \\ университет имени Н.И. Вавилова
}

В статъе исследуется вопрос прогноза изменений климата в Среднем и Нижнем Поволжве. На основе сценариев глобального потепления Межправительственной группы экспертов по изменению климата с применением методов регрессионного анализа рассчитываются прогнозные суммы осадков и эффективных температур теплого времени года для метеостаниий поволжских областей на периоды до середины и конца нынешнего века. Делается обоснованный вывод о том, ито изменения климата региона сделают невозможным ведение богарного земледелия, и единственным средством сохранения растениеводства является орошение.

Введение. В течение всего прошлого и начала нынешнего века во всем мире шло бурное развитие орошения земель, что стало одним из главных факторов обеспечения продовольственной безопасности населения нашей планеты [7]. Для засушливых регионов Среднего и Нижнего Поволжья ирригация является единственным средством повышения эффективности и обеспечения стабильности мирового сельскохозяйственного производства. Об этом писали как классики оте- 
чественной сельскохозяйственной науки [4], так и современные ученые $[1,9]$.

В то же время важнейшей экологической проблемой, вставшей перед человечеством в XXI в., является повышение температуры климатической системы нашей планеты - так называемое глобальное потепление.

Исследованием проблемы глобального потепления занимается созданная еще в 1988 г. Всемирной метеорологической организацией и ЮНЕП Межправительственная группа экспертов по изменению климата - МГЭИК (IPCC Intergovernmental Panel on Climate Change). Эта группа разрабатывает возможные сценарии изменения климата Земли. В ее последнем пятом докладе были представлены четыре сценария (табл. 1) [10].

Цель исследований - разработка прогнозов влияния глобального потепления на агроклима- тические параметры Среднего и Нижнего Поволжья - Самарской, Саратовской, Волгоградской и Астраханской областей.

Методика исследований. Базой для прогнозирования служили многолетние данные агрометеорологических наблюдений 20 метеорологических станций поволжских областей $[3,6]$, относящихся к различным по увлажнению зонам:

Самарская область и Саратовское Правобережье: Ртищево, Самара, Пенза, Аткарск, Петровск, Саратов;

Саратовское Левобережье: Ершов, Красный Кут, Пугачев, Озинки;

Волгоградская область: Волгоград, Камышин, Палласовка, Серафимович, Михайловка;

Астраханская область: Харабали, Верхний Баскунчак, Лиман, Астрахань, Досанг.

Для этих метеостанций нами были рассчи-

Таблица 1

Сценарии изменения средней температуры Земли по пятому оценочному докладу МГЭИК

\begin{tabular}{|c|c|c|c|c|c|c|}
\hline \multirow{3}{*}{ Сценарий } & \multirow{3}{*}{$\begin{array}{c}\text { Концентрация парни- } \\
\text { ковых газов в атмос- } \\
\text { фере к } 2100 \text { г., \%о }\end{array}$} & \multirow{3}{*}{$\begin{array}{c}\text { Пик выбросов } \\
\text { парниковых } \\
\text { газов, год }\end{array}$} & \multicolumn{4}{|c|}{ Параметры роста температур, ${ }^{\circ} \mathrm{C}$} \\
\hline & & & \multicolumn{2}{|c|}{ на 2046-2065 гг. } & \multicolumn{2}{|c|}{ на 2081-2100 гг. } \\
\hline & & & $\begin{array}{c}\text { среднее } \\
\text { значение }\end{array}$ & диапазон & $\begin{array}{c}\text { среднее } \\
\text { значение }\end{array}$ & диапазон \\
\hline RCP2.6 & 0,421 & $2010-2020$ & 1,0 & $0,4-1,6$ & 1,0 & $0,3-1,7$ \\
\hline RCP4.5 & 0,538 & 2040 & 1,4 & $0,9-2,0$ & 1,8 & $1,1-2,6$ \\
\hline RCP6.0 & 0,670 & 2080 & 1,3 & $0,8-1,8$ & 2,2 & $1,4-3,1$ \\
\hline RCP 8.5 & 0,936 & После 2100 & 2,0 & $1,4-2,6$ & 3,7 & $2,6-4,8$ \\
\hline
\end{tabular}

Таблица 2

Прогнозные суммы активных температур теплого периода года (апрель-октябрь) для сценариев глобального потепления

\begin{tabular}{|c|c|c|c|c|c|c|c|c|c|}
\hline \multirow{3}{*}{ Метео-станция } & \multicolumn{9}{|c|}{ Суммы активных температур, существующие и прогнозные по различным сценариям, ${ }^{\circ} \mathrm{C}$} \\
\hline & \multirow{2}{*}{$\begin{array}{l}\text { Сущест- } \\
\text { вующие }\end{array}$} & \multicolumn{4}{|c|}{ на 2046-2065 гг. } & \multicolumn{4}{|c|}{ на 2081-2100 гг. } \\
\hline & & $\begin{array}{c}\text { RCP } \\
2.6 \\
\end{array}$ & $\begin{array}{c}\text { RCP } \\
4.5 \\
\end{array}$ & $\begin{array}{c}\text { RCP } \\
6.0 \\
\end{array}$ & $\begin{array}{c}\mathrm{RCP} \\
8.5 \\
\end{array}$ & $\begin{array}{c}\text { RCP } \\
2.6 \\
\end{array}$ & $\begin{array}{c}\mathrm{RCP} \\
4.5 \\
\end{array}$ & $\begin{array}{c}\text { RCP } \\
6.0 \\
\end{array}$ & $\begin{array}{c}\text { RCP } \\
8.5 \\
\end{array}$ \\
\hline Ртищево & 2812 & 3025 & 3111 & 3089 & 3238 & 3025 & 3196 & 3281 & 3601 \\
\hline Самара & 2949 & 3162 & 3248 & 3226 & 3375 & 3162 & 3333 & 3418 & 3738 \\
\hline Пенза & 2789 & 3002 & 3087 & 3066 & 3215 & 3002 & 3173 & 3258 & 3577 \\
\hline Аткарск & 2873 & 3086 & 3172 & 3150 & 3299 & 3086 & 3257 & 3342 & 3662 \\
\hline Петровск & 2848 & 3061 & 3146 & 3125 & 3274 & 3061 & 3232 & 3317 & 3636 \\
\hline Ершов & 3130 & 3343 & 3428 & 3406 & 3556 & 3343 & 3513 & 3598 & 3918 \\
\hline Красный Кут & 3153 & 3366 & 3452 & 3430 & 3579 & 3366 & 3537 & 3622 & 3942 \\
\hline Пугачев & 3105 & 3318 & 3403 & 3382 & 3531 & 3318 & 3488 & 3574 & 3893 \\
\hline Саратов & 3016 & 3229 & 3315 & 3293 & 3442 & 3229 & 3400 & 3485 & 3805 \\
\hline Озинки & 3126 & 3339 & 3424 & 3403 & 3552 & 3339 & 3509 & 3594 & 3914 \\
\hline Волгоград & 3544 & 3757 & 3842 & 3821 & 3970 & 3757 & 3927 & 4012 & 4332 \\
\hline Камышин & 3412 & 3625 & 3710 & 3689 & 3838 & 3625 & 3796 & 3881 & 4200 \\
\hline Палласовка & 3414 & 3627 & 3712 & 3691 & 3840 & 3627 & 3798 & 3883 & 4202 \\
\hline Серафимович & 3328 & 3541 & 3626 & 3604 & 3754 & 3541 & 3711 & 3796 & 4116 \\
\hline Михайловка & 3276 & 3489 & 3574 & 3553 & 3702 & 3489 & 3659 & 3745 & 4064 \\
\hline Харабали & 3754 & 3967 & 4052 & 4031 & 4180 & 3967 & 4137 & 4222 & 4542 \\
\hline Верхний Баскунчак & 3747 & 3960 & 4045 & 4024 & 4173 & 3960 & 4130 & 4215 & 4535 \\
\hline Лиман & 3917 & 4130 & 4215 & 4194 & 4343 & 4130 & 4300 & 4385 & 4705 \\
\hline Астрахань & 3905 & 4118 & 4203 & 4182 & 4331 & 4118 & 4288 & 4374 & 4693 \\
\hline Досанг & 3862 & 4075 & 4160 & 4139 & 4288 & 4075 & 4245 & 4330 & 4650 \\
\hline
\end{tabular}




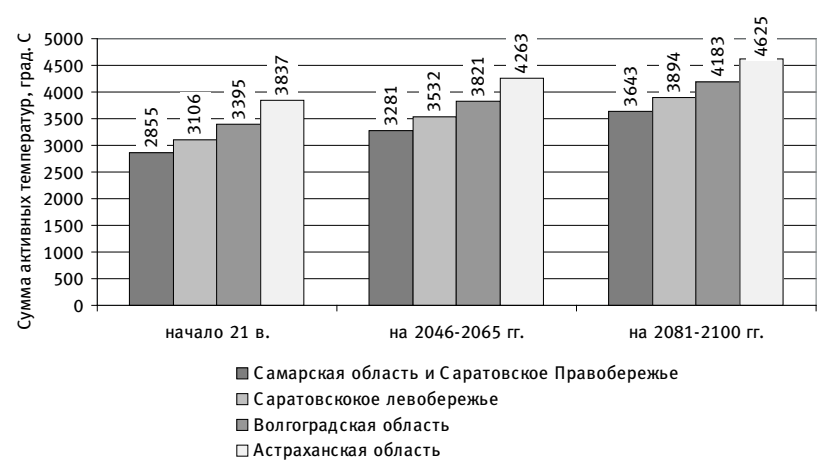

Рис. 1. Прогнозные изменения средних для зон сумм активных температур по сиенарию глобального потепления RCP 8.5

таны прогнозные суммы активных температур теплого периода года (апрель-октябрь) на середину и конец текущего века по всем сценариям глобального потепления, разработанных группой МГЭИК (табл. 2).

Результаты исследований. Анализ прогнозных изменений средних для зон сумм активных температур (рис. 1) по наиболее жесткому сценарию RCP 8.5 показывает, что уже к середине нынешнего века произойдет существенное потепление климата, в результате которого суммы температур в Волгоградской области достигнут существующих значений для Астраханской области, Саратовское Заволжье будет таким же теплым, как сейчас Волгоградская область, а Самарская область и Саратовское Правобережье как нынешнее Левобережье.

В дальнейшем, к концу XXI в., сдвиг зон увеличится с одной до двух. По теплоте летнего времени года Самарская область и Саратовское Правобережье сравняются с Волгоградской областью, а СаратовскоеЗаволжье - с Астраханской областью. Одновременно произойдет и повышение засушливости климата.

Для климатических условий поволжских областей характерна тесная обратная корреляционная связь между суммой осадков и суммой активных температур теплого времени года (коэффициент корреляции равен $-0,92)[2,5,8]$. Проведенный нами регрессионный анализ позволил установить линейную зависимость суммы осадков, мм, от суммы активных температур, ${ }^{\circ} \mathrm{C}$ (рис. 2).

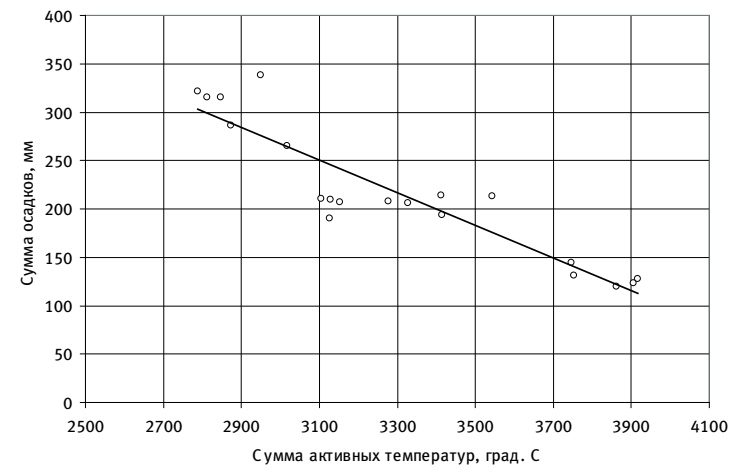

Рис. 2. Зависимость сумм осадков от сумм активных температур по метеостанииям поволжских областей
Эта зависимость имеет высокий уровень достоверности (коэффициент детерминации $R^{2} \mathrm{pa-}$ вен 0,8447 ) и описывается уравнением

$$
\sum P=-0,1683 \cdot \sum T+772,19,
$$

где $\sum P$ - сумма осадков, мм; $\Sigma T$ - сумма активных температур, ${ }^{\circ} \mathrm{C}$.

Рассчитанные по предложенной зависимости (1) прогнозные суммы осадков теплого периода года (апрель-октябрь) для разных сценариев глобального потепления и метеостанций Среднего и Нижнего Поволжья приведены в табл. 3.

Анализ средних для климатических $30 \mathrm{H}$ Поволжья прогнозных сумм осадков периода апрель-октябрь (рис. 3), рассчитанных по параметрам наиболее жесткого сценария глобального потепления RCP 8.5, показывает, что к середине XXI в. произойдет сокращение количества осадков, в результате чего в Волгоградской области они сравняются с существующими суммами осадков для Астраханской области.

Заключение. Самарская область и Саратовское Правобережье будут иметь такое же естественное увлажнение, какое отмечается в настоящее время в Саратовском Заволжье и Волгоградской области. К концу XXI в. по естественному увлажнению Астраханская и почти вся Волгоградская области станут пустынями, Саратовское Левобережье - полупустыней. Самарская область и Саратовское Правобережье практически сравняются по сумме осадков с нынешней Астраханской областью. Исходя из проведенных расчетов, можно сделать вывод о том, что в обозримом будущем изменения климатических условий существенной части Среднего Поволжья и практически всего Нижнего Поволжья сделают невозможным ведение в этой зоне богарного земледелия. В связи с этим широкое развитие ирригации в Астраханской, Волгоградской, Саратовской и, отчасти, Самарской областях является единственным средством сохранения растениеводства.

\section{СПИСОК ЛИТЕРАТУРЫ}

1. Горбачева М.П., Миркина Е.Н. Актуальность модернизации оросительных систем саратовского Заволжья // Тенденции формирования науки нового времени: сб. ст. Междунар. науч.-практ. конф. - Саратов, 2014. - С. 90-94.

2. Зависимость урожайности сельскохозяйственных культур от влагообеспеченности / А.В. Кравчук [и др.]// Основы рационального природопользования: материалы Междунар. науч.-практ. конф. - Саратов, 2013. - С. 239-242.

3. Насыров Н.Н., Корсак В.В., Соколова Т.В. Геоинформационные технологии районирования ресурсов орошаемого земледелия // Научное обозрение. 2013. - № 2. - С. 30-39.

4. Н.И. Вавилов об ирригации в Заволжье и актуальность его учения сегодня / М.С. Григоров 
Прогнозные суммы осадков теплого периода года (апрель-октябрь) для сценариев глобального потепления

\begin{tabular}{|c|c|c|c|c|c|c|c|c|c|}
\hline \multirow{3}{*}{ Метеостанция } & \multicolumn{9}{|c|}{ Суммы осадков, существующие и прогнозные, мм } \\
\hline & \multirow{2}{*}{$\begin{array}{c}\text { Сущес- } \\
\text { твую- } \\
\text { щие }\end{array}$} & \multicolumn{4}{|c|}{ на 2046-2065 гг. } & \multicolumn{4}{|c|}{ на 2081-2100 гг. } \\
\hline & & $\begin{array}{c}\text { RCP } \\
2.6 \\
\end{array}$ & $\begin{array}{c}\text { RCP } \\
4.5 \\
\end{array}$ & $\begin{array}{c}\text { RCP } \\
6.0 \\
\end{array}$ & $\begin{array}{c}\text { RCP } \\
8.5 \\
\end{array}$ & $\begin{array}{c}\text { RCP } \\
2.6 \\
\end{array}$ & $\begin{array}{c}\mathrm{RCP} \\
4.5 \\
\end{array}$ & $\begin{array}{c}\text { RCP } \\
6.0 \\
\end{array}$ & $\begin{array}{r}\mathrm{RCP} \\
8.5 \\
\end{array}$ \\
\hline Ртищево & 315 & 263 & 249 & 252 & 227 & 263 & 234 & 220 & 166 \\
\hline Самара & 338 & 240 & 226 & 229 & 204 & 240 & 211 & 197 & 143 \\
\hline Пенза & 322 & 267 & 253 & 256 & 231 & 267 & 238 & 224 & 170 \\
\hline Аткарск & 286 & 253 & 238 & 242 & 217 & 253 & 224 & 210 & 156 \\
\hline Петровск & 315 & 257 & 243 & 246 & 221 & 257 & 228 & 214 & 160 \\
\hline Ершов & 210 & 210 & 195 & 199 & 174 & 210 & 181 & 167 & 113 \\
\hline Красный Кут & 207 & 206 & 191 & 195 & 170 & 206 & 177 & 163 & 109 \\
\hline Пугачев & 211 & 214 & 199 & 203 & 178 & 214 & 185 & 171 & 117 \\
\hline Саратов & 265 & 229 & 214 & 218 & 193 & 229 & 200 & 186 & 132 \\
\hline Озинки & 190 & 210 & 196 & 200 & 174 & 210 & 182 & 167 & 113 \\
\hline Волгоград & 213 & 140 & 126 & 129 & 104 & 140 & 111 & 97 & 43 \\
\hline Камышин & 214 & 162 & 148 & 151 & 126 & 162 & 133 & 119 & 65 \\
\hline Палласовка & 194 & 162 & 147 & 151 & 126 & 162 & 133 & 119 & 65 \\
\hline Серафимович & 206 & 176 & 162 & 166 & 140 & 176 & 148 & 133 & 80 \\
\hline Михайловка & 208 & 185 & 171 & 174 & 149 & 185 & 156 & 142 & 88 \\
\hline Харабали & 131 & 105 & 90 & 94 & 69 & 105 & 76 & 62 & 8 \\
\hline Верхний Баскунчак & 145 & 106 & 91 & 95 & 70 & 106 & 77 & 63 & 9 \\
\hline Лиман & 128 & 77 & 63 & 66 & 41 & 77 & 48 & 34 & 0 \\
\hline Астрахань & 123 & 79 & 65 & 68 & 43 & 79 & 50 & 36 & 0 \\
\hline Досанг & 120 & 86 & 72 & 76 & 51 & 86 & 58 & 43 & 0 \\
\hline
\end{tabular}

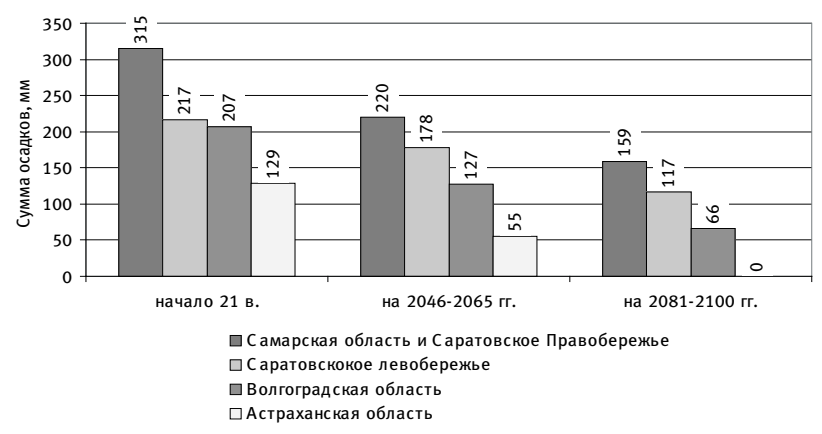

Рис. 3. Прогнозные изменения средних зональных сумм осадков теплого времени года по сиенарию глобального потепления RCP 8.5

[и др.] // Мелиорация и водное хозяйство. - 2007. № 5. - C. 15-17.

5. Никишанов А.Н., Леонтьев С.А., Свищева Е.В. Определение суммарного испарения по эмпирическим формулам // Проблемы научного обеспечения сельскохозяйственного производства и образования: сб. науч. тр. - Саратов, 2008. - С. 171-173.

6. Определение суммарного водопотребления сельскохозяйственных культур в аридных зонах / В.В. Корсак [и др.] // Научная жизнь. - 2016. - № 1. C. $41-51$.

7. Проблемы орошения сельскохозяйственных угодий и их засоления в XXI веке / В.В. Корсак [и др.] // Аграрный научный журнал. - 2016. № 8. - С. $19-24$.

8. Прокопец Р.В., Ваганова А.А., Семенов К.В. Повторяемость суховейных явлений на территории Нижнего Поволжья // Научное обозрение. - 2014. № 5. - C. 41-46.

9. Фалькович А.С., Пронько Н.А. Прогноз водносолевого режима почвогрунтов в системе проектирования и мониторинга объектов мелиорации // Аграрный научный журнал. - 2010. - № 10. - С. 62-69.

10. The IPCC's fifth assessment report (AR5). Synthesis Report 27-31 October 2014. -Режим доступа: http://www.ipcc.ch/pdf/press/ipcc_leaflets_2010/ipcc_ ar5_leaflet.pdf.

Корсак Виктор Владиславович, $\partial-p$ c.- $x$. наук, проф. кафедры «Инженерные изыскания, природообустройство и водопользование», Саратовский государственный аграрный университет имени Н.И. Вавилова. Россия.

Кравчук Алексей Владимирович, д-р техн. наук, проф. кафедры «Инженерные изыскания, природообустройство и водопользование» Саратовский государственный аграрный университет имени Н.И. Вавилова. Россия.

Прокопец Роман Викторович, канд. техн. наук, доцент кафедры «Инженерные изыскания, природообустройство и водопользование», Саратовский государственный аграрный университет имени Н.И. Вавилова. Россия.

Никишанов Александр Николаевич, канд. с.-х. наук, доцент кафедры «Инженерные изыскания, природообуст- 
ройство и водопользование», Саратовский государственный аграрный университет имени Н.И. Вавилова. Россия.

Аржанухина Екатерина Владимировна, канд. c.- $x$. наук, доцент кафедры «Инженерные изыскания, природообустройство и водопользование», Саратовский государственный аграрный университет имени Н.И. Вавилова. Россия.
410056, г. Саратов, ул. Советская, 60. Тел.: (8452) 74-96-51.

Ключевые слова: глобальное потепление; сизенарий; прогноз; агроклиматические ресурсы.

\section{SCENARIOS OF GLOBAL WARMING AND FORECASTING CHANGES OF AGROCLIMATIC RESOURCES OF THE VOLGA REGION}

Korsak Victor Vladislavovich, Doctor of Agricultural Sciences, Professor of the chair "Engineering Surveys, Environmental Engineering and Water Management", Saratov State Agrarian University named after N.I. Vavilov. Russia.

Kravchuk Alexey Vladimirovich, Doctor of Technical Sciences, Professor of the chair "Engineering Surveys, Environmental Engineering and Water Management", Saratov State Agrarian University named after N.I. Vavilov. Russia.

Prokopets Roman Viktorovich, Candidate of Technical Sciences, Associate Professor of the chair "Engineering Surveys, Environmental Engineering and Water Management", Saratov State Agrarian University named after N.I. Vavilov. Russia.

Nikishanov Aleksandr Nikolaevich, Candidate of Agricultural Sciences, Associate Professor of the chair "Engineering Surveys, Environmental Engineering and Water Management", Saratov State Agrarian University named after N.I. Vavilov. Russia.
Arjanuhina Ekaterina Vladimirovna, Candidate of Agricultural Sciences, Associate Professor of the chair "Engineering Surveys, Environmental Engineering and Water Management", Saratov State Agrarian University named after N.I. Vavilov. Russia.

Keywords: global warming; scenario; forecasting; agroclimatic resources.

The article studies the issue of forecasting climate changes in the Middle and Lower Volga region. Based on the IPCC global warming scenarios, with the use of regression analysis methods, the forecast sums of precipitation and effective temperatures of the warm season for meteorological stations in the Volga region for the periods up to the middle and the end of the present century are calculated. A reasonable conclusion is drawn that climate change in the region makes it impossible to conduct dry-land farming and the only way to preserve crop production is irrigation.

Удк 631.3:635.21

\section{ТЕОРЕТИЧЕСКОЕ ОБОСНОВАНИЕ ПРОЦЕССОВ ПЕРЕМЕЩЕНИЯ КЛУБНЕЙ КАРТОФЕЛЯ ПО КАЛИБРУЮЩЕЙ ПОВЕРХНОСТИ, ОБРАЗОВАННОЙ ПРАВИЛЬНЫМИ ШЕСТИУГОЛЬНИКАМИ}

\section{МИРКИНА Елена Николаевна, Саратовский государственный аграрный университет имени} Н.И. Вавилова

БЫЧкОВА Наталья Александровна, Профессионально-педагогический колледж ФГБОУ ВО СГТУ имени Гагарина Ю.А.

Изложены теоретические исследования процесса взаимодействия клубней различной формы с шестиугольными отверстиями, был проведен анализ сил, действующих на клубни с поперечными сечениями округлой и эллипсоидной формы.

Введение. Роль картофеля в решении мировой продовольственной проблемы очень велика, поскольку это одна из важнейших продовольственных культур с высокой питательной ценностью и продуктивностью. Как в России, так и в развитых странах одно из ведущих мест занимает возделывание картофеля в сельскохозяйственном производстве.

Картофель занимает особое место среди продуктов питания, составляющих основу продовольственного рынка России, а также оказывает существенное влияние на обеспечение продовольственной безопасности страны.

Государство прочно сохраняет за собой лидирующее положение в мире по уровню среднегодового валового производства картофеля, оставаясь самым крупным производителем (более половины валового производства).

По общим энергетическим запасам картофель занимает пятое место после пшеницы, ку- курузы, риса, ячменя. В его клубнях содержится в среднем 75-80 \% воды и 20-25\% сухих веществ, в том числе от 14 до $22 \%$ крахмала, $2-3 \%$ белка, 0,2-0,3 \% жира, различные витамины, аминокислоты, углеводы и более 20 минеральных элементов, к основным из которых относятся кальций, фосфор, магний, железо.

Картофель служит также отличным кормом для сельскохозяйственных животных. При урожайности 170-200 ц/га картофель дает 5-6 тыс. к. ед. с 1 га. На корм сельскохозяйственных животных используют и отходы, получаемые при переработке картофеля для пищевых целей.

Однако производство этой культуры в России в последние годы практически не расширяется. Во многих регионах страны потери выращенного урожая при уборке, перевозке и хранении составляют более $25 \%$, что создает определенные сложности в снабжении населения страны, 